\title{
Effect of Mentorship Program on Mentees' Psychosocial Development
}

\author{
Azman Ismail ${ }^{1 *}$, Nor'Ain Abdullah², Ahmad Azan Ridzwan ${ }^{3}$, \\ Wan Nur Ain Wan Ibrahim ${ }^{4}$, Yusof Ismail ${ }^{5}$ \\ ${ }^{1}$ Universiti Kebangsaan Malaysia, Faculty of Economics \& Management, 43600 Bangi, Selangor Darul \\ Ehsan, Malaysia \\ 2Universiti Kebangsaan Malaysia, Institute Islam Hadhari, 43600 Bangi, Selangor Darul Ehsan, \\ Malaysia \\ ${ }^{3}$ University Pertahanan Nasional Malaysia, Faculty of Defence \& Management Studies, 43600 Bangi, \\ Selangor Darul Ehsan, Malaysia \\ ${ }^{4}$ University Pertahanan Nasional Malaysia, Center for Graduate Studies, 43600 Bangi, Selangor Darul \\ Ehsan, Malaysia \\ ${ }^{5}$ International Islamic University Malaysia, Economics \& Management Sciences. 53100 Kuala Lumpur. \\ Malaysia \\ *E-mail address: ${ }^{1}$ azisma80@gmail.com, ${ }^{2}$ norainabdullah_ukm@yahoo.com, \\ 3azan6142@yahoo.com, 'zanurain@yahoo.com, 5yusof.edu@gmail.com
}

\begin{abstract}
The study investigates the role of mentorship in enhancing mentees' psychosocial development. It utilized self-administered questionnaires completed by undergraduate military students at a public higher learning institution in Malaysia. The outcomes of SmartPLS path model analysis revealed two important findings: firstly, communication insignificantly correlated with psychosocial development. Secondly, support significantly correlated with psychosocial development. The results confirm that communication does not act as an important determinant of mentees' psychosocial development. However, support does act as an important psychosocial development in the studied organization. This paper also provides discussion, implications and conclusion.
\end{abstract}

Keywords: mentoring; communication; support; psychosocial development

\section{INTRODUCTION}

Mentorship is a broad term and may be interpreted according to formal definition and through the use of images viewpoints. The image of the old, bearded, wise man can be traced back in Greek literature when Odysseus referred his son Telemachus for guidance in preparation for Trojan War (Ismail \& Khian Jui, 2013; Ismail \& Ridzuan, 2012; Megginson \& Clutterbuck, 1995). The word mentor may also refer to a "father figure" who sponsors, guides and develops a younger person (Ehrich, Lisa, Hansford \& Tennent, 2004; Ismail \& Khian Jui, 2013). Mentors and mentees have played a significant role in teaching, inducting and developing the skills and talents of mentee. Mentorship has been receiving substantial attention among practitioners and academics as a means to professional and personal development (Little, Kearney \& Britner, 2010) and/or counseling services (Gregson, 1994; 
Zuraidah, Zaiton, Masiniah, Jamayah, Sabasiah \& Abdul Halim, 2004). In this context, mentors are often selected based on wisdom, experiences and trustworthiness where their main functions are to guide mentees in understanding the complexity of different organizational culture, norms and expectations (Ismail, Hasbullah, Bakar \& Boerhanoeddin, 2005; Ismail, Hasbullah, Bakar, Ahmad \& Junoh, 2006; Ismail \& Ridzuan, 2012; Little et al., 2010).

Mentorship has certainly been one of the terms in vogue in the 1990s. Mentorship from an organizational perspective is often seen as a learning tool which encourages relationship between incumbent and a novice. It also acts as an instrument to develop group and/or individuals' potentials in carrying out duties and responsibilities, learning new techniques, and safeguarding well-being of mentees (Cummings \& Worley, 2009; Ismail \& Khian Jui, 2013; David Megginson \& David Cluterbuck, 1995; Little et al., 2010). According to Ragins and Kram (2007) mentorship has two important functions. Firstly, mentor may offer career function that includes challenging assignment, visibility to management and sponsorship. Secondly, it provides psychosocial function by enhancing a protégé's self-confidence and addressing other interpersonal concerns of the relationship (Ragoms \& Cotton, 1999). Currently, mentorship program in the organization is designed and implemented according to the organizational contexts accommodating beliefs, policy orientations, stresses, strengths and weaknesses (Irving et al., 2003; Ismail et al., 2005, 2006; Ismail \& Khian Jui, 2013; Ismail, Nik Daud, Hassan \& Khian Jui, 2010; Santos \& Reigadas, 2002, 2005). It happened because there is no one best mentorship model that is suitable to the organization.

As stated by many scholars like Tennenbaum, Crosby \& Gliner (2001), Bernier, Larose \& Soucy (2005), Ismail \& Ridzuan (2012), and Ismail \& Khian Jui (2013), successful mentorship programs consist of two salient practices, i.e., communication and support. Comunication is often viewed as a process of acting on information by creating meaning through verbal and nonverbal messages (Oluga, Adewusi \& Babalola, 2001, Beebe \& Ivy,2004). In the context of university mentorship program, communication is specifically defined as process wherein mentors openly deliver information about the objective and benefits of attending mentorship programs and providing performance feedback (Fox, Stevenson Connelly, Duff \& Dunlop, 2010; Ismail et al., 2005, 2006; Santos \& Reigadas, 2005). The second factor for a successful mentorship is support given by the mentor to the mentees (Mentor, 2009). Support is broadly defined as mentors providing emotional support (e.g., to enable mentees to acquire new knowledge, skills, and attitudes, and guide them to properly practice in daily life) and instrumental support (e.g., assisting mentees to adapt to campus environments) at varying times to mentees (Davis, 2007; Fox et al., 2010; Stewart \& Knowles, 2003).

Surprisingly, recent studies in university/faculty mentorship programs disclose that if mentors appropriately implement such mentorship practices this may have a positive impact on mentees' outcomes, especially psychosocial development (Allen \& Finkelstein, 2003; Dutton, 2003; Ismail \& Khian Jui, 2013). The word "psychosocial" in a higher education is often viewed as students making preparations to adapt to campus life which entails social integration, well being and self confidence (Dutton, 2003; Pope, 2002; Santos \& Reigadas, 2005). Within a mentorship program model, many scholars think that communication, support and psychosocial are different, but nevertheless strongly interrelated concepts. For example, the ability of mentors to properly implement comfortable communication and provide adequate support have been essential factors that may enhance positive mentee outcomes, especially psychosocial development (Allen \& Finkelstein, 2003; Dutton, 2003). 
Even though the nature of this relationship is significant, little has been left unexplained about the role of mentorship program as an important determinant of mentee outcomes in the mentorship program research literature (Allen \& Finkelstein, 2003; Bernier et al., 2005; Ismail \& Khian Jui, 2013). Many scholars argue that this situation is related to the emphasis of many previous on the internal properties of mentorship program, employment of a simple survey method to explain different respondent perceptions toward particular mentorship program models and usage of a simple correlation analysis to measure the strength of association between mentorship program and mentees' psychosocial development. Hence, these studies have not provided sufficient information to be used as guidelines by practitioners in formulating strategic action plans to improve the design and administration of mentorship programs in dynamic environment of higher learning institutions (Bernier et al., 2005; Dutton, 2003; Ismail \& Khian Jui, 2013; Ismail \& Ridzuan, 2012). This phenomenon has motivated the researchers to further explore the nature of this relationship.

\section{OBJECTIVE OF THE STUDY}

This study has dual objectives: first, is to measure the relationship between communication and mentees' psychosocial development. Second, is to measure the relationship between support and mentees' psychosocial development.

The paper is structured to deliberate on three important issues: first, it discuses relevant theoretical and empirical evidence supporting the hypothesized model in the literature review section. Second, it explains results of data analysis in the finding section. Finally, it discusses the results in the light of the literature, shares some discussion, suggests some implications and draws conclusions of the study.

\section{LITERATURE REVIEW}

\subsection{Relationship between Mentorship Program and Mentees'}

\section{Psychosocial Development}

Several studies were conducted using a direct effects model to investigate mentorship program based on different samples like perceptions of 88 participants of a large south eastern university in United States (Allen \& Finkelstein, 2003), perceptions of 18 students at University of Brighton, United Kingdom (Dutton, 2003), perceptions of 110 students in Canadian colleges (Bernier et al., 2005) and perceptions of 196 students in teaching based higher learning institutions in Sarawak (Ismail et al., 2013). These studies found that the ability of mentors to properly implement comfortable communication and provide adequate support in formal and/or informal mentorship relationships had been important determinants of mentees' psychosocial development in the respective organizations (Allen \& Finkelstein, 2003; Bernier et al., 2005; Dutton, 2003; Ismail et al., 2013).

These studies support the notion of adult learning theory. For example, Erikson's (1963) theory of psychosocial development proposes six basic concepts that strongly influenced the development of young adult's life span, namely, stage of development, development tasks, psychosocial crises, a central process for resolving the crisis at each stage, a radiating network of significant relationships, and coping. If a young adult is able to appropriately change 
his/her life span, this may lead to improved psychosocial development (Newman, 2012). Meanwhile, Chickering's (1969) vector theory of identity development suggests seven factors which strongly affect the development of young adult identities which are developing competence, managing emotions, becoming autonomous, developing interpersonal relationships, establishing identity, developing purpose, and developing integrity. These theories argue that mentors help mentee achieve change in life span and gain better life span if mentors are able to appropriately implement comfortable communication and provide adequate support in mentorship activities. Mentoring may also lead to an enhanced mentees' psychosocial development in higher education institutions (Allen \& Finkelstein, 2003; Bernier et al., 2005; Dutton, 2003).

\subsection{Conceptual Framework and Research Hypothesis}

The literature has been used as foundation of developing a conceptual framework as illustrated in Figure 1.

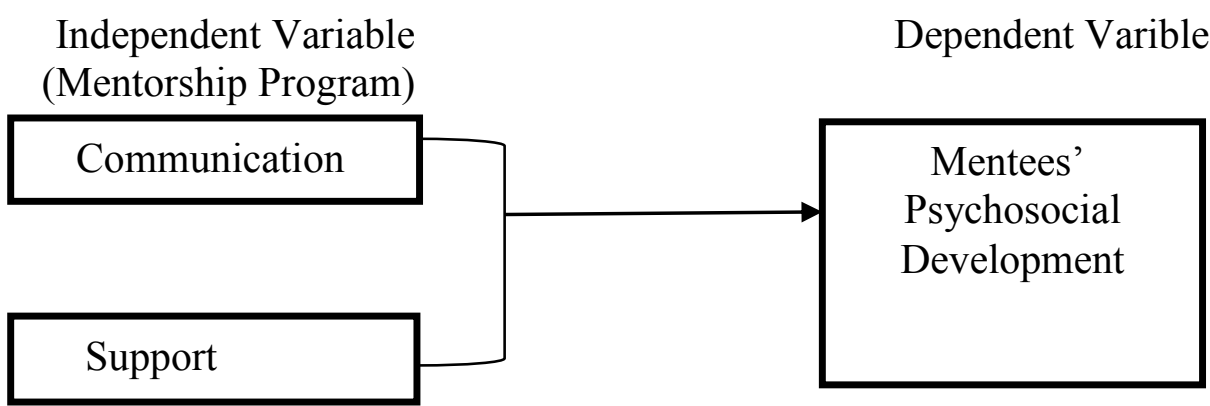

Figure 1. Conceptual Framework.

Based on the framework, it can be hypothesized that:

H1: There is a positive relationship between communication and mentees' psychosocial development.

$\mathrm{H} 2$ : There is a positive relationship between support and mentees' psychosocial development.

\section{METHODOLOGY}

\section{Research Design}

This study used a cross-sectional research design which allows the researchers to integrate the mentorship program literature, unstructured interview, and the actual study as the primary joint procedure to gather data for this study. Such approaches are recommended to enable researchers to gather accurate data, decrease bias and increase the quality of data collected (Sekaran \& Bougie, 2010; Zikmund, 2000). This study was conducted at a public higher learning institution in Malaysia. For confidential reasons, the name of the organization is kept anonymous. At the initial stage, survey questionnaires were prepared by incorporating input from mentorship program literature. After that, unstructured interviews were conducted involving 10 senior graduating students $\left(2^{\text {nd }}\right.$ year and above for three-year bachelor's programs), comprising five students from public and five from private institutions in order to 
understand the nature of communication and support practiced in the mentorship programs, psychosocial development, and relationship between these variables in the organization. Information gained from the interviews was used to improve the content and format of survey questionnaire for an actual study. Further, a back translation technique was employed to translate the survey questionnaires into English and Malay languages in order to enhance the validity and reliability of research findings (Sekaran \& Bougie, 2010; Zikmund, 2000).

\section{Measures}

This survey questionnaire is divided into three sections. First section is about communication. It was measured using 5 items adapted from mentorship communication system literature (Foxon, 1993; Ismail et al., 2005, 2006, 2010; Ismail \& Ridzuan, 2012; Sullivan, 2000; Yamnill \& McLean, 2001; Young \& Cates, 2005). The dimensions used to measure communication were mentees' understanding, mentorship goal, good values, critical thinking and respect. Second section deals with support. It was measured using 3 items that were adapted from mentorship support system literature (Chiaburu \& Takleab, 2005; Langhout et al., 2004; Ismail et al., 2005, 2006; Ismail \& Ridzuan, 2012; Rayle, Kurpius \& Arredondo, 2006; Tsai \& Tai, 2003; Vieno, Santinello, Pastore \& Perkins, 2007). The dimensions used to measure support were helping, suggestion and toleration. Third section deals with psychosocial development. It was measured using 3 items that were modified from undergraduate student psychosocial literature (Allen, Day \& Lentz, 2006; Greenberger \& Wang, 2002; Ismail, A., \& Khian Jui, 2013; Noe, 1988; Noe,). The dimensions used to measure psychosocial were confident, adaptation, and sharing personal experiences. All items used in the questionnaires were measured using a 7-item Likert scale ranging from "strongly disagree/dissatisfied" (1) to "strongly agree/satisfied" (7). Demographic variables were used as controlling variables because this study focused on student attitudes.

\section{Sample}

A convenient sampling technique was employed to distribute 250 survey questionnaires to undergraduate military students in the studied organization. This sampling technique was chosen because the management of the organizations did not allow the researchers to perform random sampling procedures. Out of the total number, 107 questionnaires were returned to the researchers, yielding 42.8 percent response rate. The survey questionnaires were answered by participants based on their consents and on voluntarily basis.

\section{Data Analysis}

The survey questionnaire data was analyzed using the SmartPLS 2.0. This statistical package has several advantages where it may deliver latent variable scores, avoid small sample size problems, estimate every complex models with many latent and manifest variables, hassle stringent assumptions about the distribution of variables and error terms, and handle both reflective and formative measurement models (Henseler et al., 2009; Ringle et al., 2005). The SmartPLS path model was employed to assess the magnitude and nature of the relationship between many independent variables and one or more dependent variables in the structural model using standardized beta $(\beta)$ and $t$ statistics. The value of $\mathrm{R}^{2}$ is used as an indicator of the overall predictive strength of the model. The value of $\mathrm{R}^{2}$ is interpreted as follows: 0.19 (weak), 0.33 (moderate) and 0.67 (substantial) as suggested by Chin (1998), and 
Henseler et al. (2009). A global fit measure was conducted to validate the adequacy of PLS path model based on Wetzel, Kneebone, Woloshynowych, Moorthy \& Darsy's (2006) global fit measure. If results of testing hypothesized model exceed the cut-off value of 0.36 for large effect sizes of $\mathrm{R}^{2}$, then they adequately support the PLS path model globally.

\section{RESULTS}

\section{Sample Profile}

The respondents'characteristics show that majority of the respondents were males $(65.4$ $\%$ ), with age ranging from 20 to 22 years $(75.7 \%), 41.1 \%$ of the sample comprises first year students and followed by second year students $(32.7 \%)$, almost half of the students achieve CGPA between 3.01 and 3.50 (48.5\%), and $77.6 \%$ of the sample belong to Faculty of Defence \& Management Studies.

Table 1. Respondents' Characteristics ( $\mathrm{n}=107)$.

\begin{tabular}{|c|c|c|}
\hline Sample Profile & Sub-Profile & Percentage \\
\hline Gender & Male & 65.4 \\
& Female & 34.6 \\
\hline Age & 19 to 21 years old & 10.3 \\
& 22 to 24 years old & 75.7 \\
& 25 to 27 years old & 14.0 \\
\hline Faculty & Faculty of Engineering & 14.0 \\
& Faculty of Defence \& Management & 77.6 \\
& Studies & 8.4 \\
& Faculty of Science \& Defence & \\
& Technology & 41.1 \\
& First Year & 32.7 \\
& Second Year & 11.27 \\
& Third Year & 15.0 \\
& Others & 0.9 \\
& Below 1.5 & 7.5 \\
& CGPA 2.01-2.50 & 41.1 \\
& CGPA 2.51-3.00 & 45.8 \\
& CGPA 3.01-3.50 & 4.7 \\
\hline
\end{tabular}

Source: Research Findings

\section{Validity and Reliability Analyses}

The confirmatory factor analysis was conducted to assess the psychometric properties of survey questionnaire data. Table 2 shows results of convergent and discriminant validity analyses. All constructs had values of average variance extracted (AVE) larger than 0.5, which is within the acceptable standard of convergent validity (Henseler et al., 2009). All constructs also had the values of AVE square root (in diagonal) greater than the squared 
correlation with other constructs (in off diagonal). This shows that all constructs met the acceptable standard of discriminant validity.

Table 2. The Results of Convergent and Discriminant Validity Analyses.

Source: Research Findings

\begin{tabular}{|c|c|c|c|c|}
\hline Variable & AVE & Communication & Support & Psychosocial \\
\hline Communication & 0.6033 & $\mathbf{0 . 7 7 6 7}$ & & \\
\hline Support & 0.7111 & 0.6357 & $\mathbf{0 . 9 1 8 3}$ & \\
\hline Psychosocial & 0.6026 & 0.4405 & 0.5938 & $\mathbf{0 . 7 7 6 3}$ \\
\hline
\end{tabular}

Table 3 shows the factor loadings and cross loadings for different constructs. The correlation between items and factors had higher loadings than other items in the different constructs, as well as the loadings of variables were greater than 0.7 in their own constructs in the model are considered adequate (Henseler et al., 2009), thus the validity of measurement model met the criteria. The values of composite reliability and Cronbach's Alpha were greater than 0.8 , indicating that the instrument used in this study had high internal consistency (Henseler et al., 2009; Nunally \& Benstein, 1994).

Table 3. The Results of Factor Loadings and Cross Loadings for Different Construct.

\begin{tabular}{|c|c|c|c|c|}
\hline Construct & Communication & Support & Psychosocial & $\begin{array}{c}\text { Composite } \\
\text { Reliability }\end{array}$ \\
\hline Communication & $\mathbf{0 . 7 0 9 7}$ & 0.3926 & 0.2619 & 0.8835 \\
Comt1 & $\mathbf{0 . 8 1 9 0}$ & 0.4153 & 0.3324 & \\
Comt2 & $\mathbf{0 . 7 8 0 7}$ & 0.5149 & 0.3012 & \\
Comt3 & $\mathbf{0 . 8 2 2 8}$ & 0.6146 & 0.4787 & \\
Comt4 & $\mathbf{0 . 7 4 5 5}$ & 0.4778 & 0.2469 & \\
Comt5 & & & & 0.8807 \\
\hline Support & 0.4892 & $\mathbf{0 . 8 0 9 8}$ & 0.4574 & \\
Spt1 & 0.5093 & $\mathbf{0 . 8 5 1 6}$ & 0.4641 & \\
Spt2 & 0.5983 & $\mathbf{0 . 8 6 7 4}$ & 0.5681 & \\
Spt3 & 0.2003 & 0.3691 & $\mathbf{0 . 7 4 1 1}$ & \\
\hline Psychosocial & 0.3753 & 0.5121 & $\mathbf{0 . 7 6 7 3}$ & \\
Psy1 & 0.4134 & 0.4788 & $\mathbf{0 . 8 1 8 4}$ & \\
Psy2 & &
\end{tabular}

Source: Research Findings

\section{Analysis of Research Constructs}

Table 4 shows that the mean values for the variables range from 5.4 to 5.7, showing that the levels of communication, support, psychosocial and academic performance are ranging from high (4) to highest levels (7). The correlation coefficients for the relationship between the independent variable (i.e., communication and support) and the dependent variable (i.e., psychosocial development) are less than 0.90 , indicating the data are not affected by serious collinearity problem (Hair, Anderson, Tatham \& Black, 2006). 
Table 4. Pearson Correlation Analysis and Descriptive Statistics.

\begin{tabular}{|c|c|c|c|c|c|c|}
\hline \multirow{2}{*}{\multicolumn{2}{|c|}{ Variable }} & \multirow[t]{2}{*}{ Mean } & \multirow[t]{2}{*}{$\begin{array}{l}\text { Standard } \\
\text { Deviation }\end{array}$} & \multicolumn{3}{|c|}{$\begin{array}{c}\text { Pearson Correlation } \\
\text { Analysis (r) }\end{array}$} \\
\hline & & & & 1 & 2 & 3 \\
\hline & Communication & 5.7 & .70 & 1 & & \\
\hline 2. & Support & 5.4 & .79 & $.63^{* *}$ & 1 & \\
\hline . & Psychosocial & 5.4 & .73 & $.40^{* *}$ & $.54^{* *}$ & 1 \\
\hline
\end{tabular}

Note: Significant at $* * p<0.01 \quad$ Reliability Estimation is Shown in a Diagonal

Source: Research Findings

\section{Testing Hypotheses 1 and 2}

Figure 2 shows the outcomes of SmartPLS path model for testing the direct effects model. In terms of exploratory analysis of the model, the inclusion of communication and support in the analysis had explained 26 percent of the variance in dependent variable. Specifically, the results of testing hypothesis highlighted two important findings: first, communication is insignificantly correlated with psychosocial development $(\beta=0.11 ; \mathrm{t}=1.41)$, therefore H1 is accepted. Second, support is significantly correlated with psychosocial development $(\beta=0.53 ; t=6.01)$, therefore $\mathrm{H} 2$ is also accepted. This result demonstrates that communication does not act as an important determinant of mentees' psychosocial development, but support does act as an important determinant of mentees' psychosocial development in the studied organization.

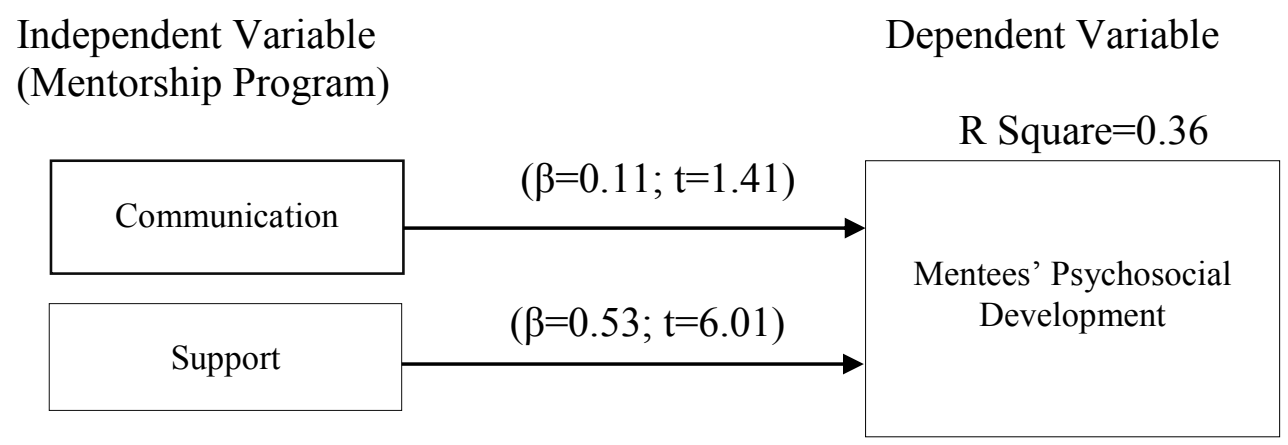

Note: Significant at $t>1.96$

Figure 2. Outcomes of the SmartPLS Path Analysis Showing the Relationship between Mentorship Program and Mentees' Psychosocial Development.

In order to determine a global fit PLS path model, a global fit measure (GoF) was carried out based on Wetzel et al.'s (2009) guideline as follows: GoF=SQRT MEAN (Communality of Endogenous) $x$ MEAN $\left.\left(\mathrm{R}^{2}\right)\right\}=0.48$, signifying that it exceeds the cut-off value of 0.36 for large effect sizes of $\mathrm{R}^{2}$. This result confirms that the PLS path model has better explaining power in comparison with the baseline values ( $\mathrm{GoF}$ small $=0.1$, GoF medium $=0.25$, GoF large $=0.36$ ). It also provides strong support to validate the PLS model globally (Wetzel et al., 2006). 


\section{DISCUSSION AND IMPLICATIONS}

This study demonstrates that mentorship program does act as an important determinant of mentees' psychosocial development in the studied organization. In the context of this study, mentors have appropriately planned and implemented mentorship activities according to broad policies and procedures formulated by the stakeholder. According to the majority of respondents, the levels of communication, support and psychosocial development are high in the organization. This situation indicates that the ability of mentors to appropriately implement communication and support in mentorship activities may lead to an enhanced mentees' psychosocial development in the organization.

These findings provide three major implications: theoretical contribution, robustness of research methodology, and practical contribution. From the persective of theoretical contribution, the results of this study display two important findings: first, support has been an important determinant of mentees' psychosocial development in the organizational sample. This result is also consistent with studies by Allen and Finkelstein (2003), Dutton (2003), Bernier et al. (2005), and Ismail et al. (2013). Conversely, communication has not been an important determinant of mentee's psychosocial development. A careful observation of the unstructured interviewed outcomes show that this result may be affected by external factors: first, the participating respondents have different personal and academic backgrouds. This phenomenon may create different judgements and values among respondents about the benefits of mentorship programs. Second, the interviewed respondents might have perceived that unequal distributions of power in a military environment may create high power distance and communication gap in the mentorship activities. Finally, the interviewed respondents viewed that mentors also have different personal and service backgrounds which may create differing capabilities among mentors to practice comfortable communication in mentorship activities. These factors may overrule the effectiveness of communication practices in the higher learning institution mentorship program.

With respect to the robustness of research methodology, the survey questionnaires used in this study have met the acceptable standards of validity and reliability analyses. This attribute may lead to the production of accurate and reliable findings.

With regard to practical contribution, the findings of this study may be used as guidelines by practitioners to improve the management of mentorship programs in higher learning institutions. In order to realize these objectives, management should consider the following aspects: firstly, to improve training content and methods for mentors in order to enhance their competencies in interpersonal communication, teaching, counseling and guiding different mentee backgrounds. Secondly, to form mentorship groups based on students' academic performance in order to facilitate mentors making proper plans to fulfill the requirements of mentees who have different levels of academic performance. Thirdly, to ensure that mentors plan and implement the various kinds of attractive activities in order to motivate mentees to commit with the programs. Fourth, to remind mentors to train high performing students to be co-mentors and/or role models to other students in formal and/or informal mentorship activities. If the management pay special attention to the suggestions, the former may be able to strongly encourage mentees to support the goals of mentorship program in higher learning institutions. 


\section{CONCLUSION}

This study tested a theoretical framework that was developed based on the research on higher education mentorship program. The confirmatory factor analysis showed that the measurement scale used in this study met the acceptable standards of validity and reliability analyses. Furthermore, the outcomes of SmartPLS path model analysis confirmed that communication was not significantly correlated with mentees' psychosocial development, thus rejecting $\mathrm{H} 1$. This result may be affected by external factors such as different judgements and values of the participating respondents about the benefits of mentorship programs, high power distance culture increases communication gap in the mentorship activities, and unequal capabilities among mentors to practice comfortable communication in mentorship activities. These factors may override the effectiveness of communication practices in the higher learning institution mentorship program. However, support was significantly correlated with mentees' psychosocial development, therefore giving support to H2. These results are supporting and broadening studies mostly published in Western countries. Mentorship program does act as an important determinant of mentees' psychosocial development in the organization under study. Therefore, current research and practice within the higher education student development model need to consider communication and support as strategic dimensions of organizational mentorship program. This study further suggests that the capability of mentors to appropriately plan and manage formal and/or informal mentorship activities will induce subsequent positive mentee outcomes (e.g., self-efficacy, career and leadership). Thus, these positive outcomes may help maintain and enhance the level of academic performance of higher learning institutions.

\section{REFERENCES}

[1] Allen, T. D., Day, R., \& Lentz, E. 2005. The role of interpersonal comfort in mentorship relationships. Journal of Career Development, 31(3), pp. 155-169.

[2] Allen, T. D., \& Finkelstein, L. M. 2003. Beyong mentorship: Alternative sources and functions of developmental support. The Career Development Quarterly, 51, pp. 346355 .

[3] Beebe, A. S., Beebe, J. S., \& K. Ivy. 2004. Communication: Principle for a Life Time. Bostan: Pearson.

[4] Bernier, A., Larose, S., \& Soucy, N. 2005. Academic mentoring in college: The interactive role of student's and mentor's interpersonal dispositions. Research in Higher Education, 46(1), pp. 29-51.

[5] Chiaburu, D. S. \& Takleab, A. G. 2005. Individual and contextual influences on multiple dimension of training effectiveness. Journal of European Industrial Training, 29(8), pp. 604-626.

[6] Chickering, A. W. 1969. Education and identity. San Francisco: Jossey-Bass.

[7] Chin, W.W. 1998. The partial least squares approach to structural equation modelling. In Hoyle, R.H. (eds.) Statistical Strategies for Small Sample Research, (pp. 307-341). California: Sage Publication, Inc. 
[8] Cummings, T. G., \& Worley, C. G. 2009. Organization development \& change. $\left(9^{\text {th }}\right.$ Edition). Masan: South-Western Cengage Learning.

[9] Davis, D. J. 2007. Access to academe: The importance of mentoring to black students. Negro Educational Review, 58(3/4), pp. 217-279.

[10] Dennison, S. 2000. A win-win peer mentoring guidebook: A practical manual for designing and managing a mentoring program. Clemson, SC: National Droput Prevention Center.

[11] Dutton, C. 2003. Mentoring: The contextualization of learning- mentor, protégé and organizational gain in higher education. Education and Training, 45(1), pp. 22-29.

[12] Ehrich, L. C., Hansford, B., \& Tennent, L. (2004). Formal mentoring programs in education and other professions: A review of the literature. Educational Administration Quarterly, 40(4), pp. 518-540.

[13] Erikson E. 1968. Identity: Youth and crisis. Norton, New York.

[14] Fox, A., Stevenson, L., Connelly, P., Duff, A., \& Dunlop, A. 2010. Peer-mentoring undergraduate accounting students: The influence on approaches to learning and academic [15] performance. Active Learning in Higher Education, 11(2), pp. 145-156.

[15] Foxon, M. 1993. A process approach to the transfer of training: The impact of motivation and supervisor support on transfer maintenance. Australian Journal of Educational Technology, 9(2), pp. 130-143.

[16] Friday, E., \& Friday, S. S. 2002. Formal mentoring: Is there a strategic fit?. Management Decision 40(2), pp. 152-157.

[17] Gregson, K. 1994. Mentoring. Employee Counseling Today 6(4), pp. 26-27.

[18] Hair, J. F., Anderson, R. E., Tatham, R. L., \& Black, W. C. 2006. Multivariate data analysis. New Jersey: Prentice Hall International.

[19] Hansford, B., \& Ehrich, L. C. 2006. The principalship: How significant is mentoring? Journal of Educational Administration, 44(1), pp. 36-52.

[20] Hansford, B., Tennent, L., \& Ehrich, L. 2003. Educational mentoring: Is it worth the effort? Educational Research \& Perspectives, 30(1), pp. 42-75.

[21] Henseler, J., Christain, M., Ringle,R,. \& Sinkovics. 2009. The use of Partial Least Square Path modeling in international Marketing. Advances in International Marketing, 20, pp. 277-319

[22] Irving, E. S., Moore, W. D., \& Hamilton, R. J. 2003. Mentoring for high ability school students. Education and Training, 45(2), pp. 100-109.

[23] Ismail, A., Hasbullah, K., Bakar, R. A., \& Boerhanoeddin, A. 2005. Amalan komunikasi dalam program mentoring: Pemindahan pengetahuan, kemahiran dan kebolehan memainkan peranan bersyarat dalam organisasi. Jurnal Pendidikan, Universiti Malaya, pp. 93-115.

[24] Ismail, A., Hasbullah, K., Bakar, R. A., Ahmad, R., \& Junoh, A. M. 2006. Pemindahan pengetahuan, kemahiran dan kebolehan mempengaruhi kesan amalan komunikasi antara mentor dan mentee: Satu kajian di sebuah institusi pengajian tinggi awam di Malaysia Timur. Jurnal Kemanusiaan, 7, pp. 33-55. 
[25] Ismail, A., \& Khian Jui, M.K. (2013). Relationship between Mentoring Program and Mentee Outcomes in Higher Education. The Proceeding of the 1st CHREST International Conference on Labour Market Transformation and Human Resource Development, 8-9 Jan 2013, Kuala Lumpur, Malaysia.

[26] Ismail, A., Amir, R. \& Khian Jui, M.K. (2013). An Empirical study of the Relationship between Mentoring Program and Mentee's Psychosocial Development. Acta Universitatis Danubius, 7(1).

[27] Ismail, A., Nik Daud, N.G., Hassan, A.A., \& Khian Jui, M.K. (2010). Relationship between Mentoring Program Characteristics and Mentees' Career: A Study in a Malaysian Public University. The Romanian Economic Journal, XIII (38), pp. 27-50.

[28] Ismail, A., \& Ridzuan, A.A. (2012). Relationship between mentoring program and academic performance. The mediating effect of self-efficacy. The Proceeding of the $3 \mathrm{rd}$ International Conference on Business and Economics Research (ICBER), 12-13 March 2012, Indonesia

[29] Johnson, S. K., Geroy. G. D., \& Griego, O. V. (1991). The mentoring model theory: Dimensions in mentoring protocols. Career Development International, 4 (7), pp. 384391.

[30] Langhout, R. D., Rhodes, J. E., \& Osborne, L. N. (2004). An exploratory study of youth mentoring in an urban context: Adolescents' perceptions of relationship styles. Journal of Youth and Adolescence, 33(4), pp. 293-306.

[31] Little, C. A., Kearney, K. L., \& Britner, P. A. 2010. Students' self-concept and perceptions of mentoring relationships in a summer mentorship program for talented adolescent. Roeper Review, 32, pp.189-199.

[32] Mentor. 2009. Elements of Effective Practice for Mentoring. MetLife Foundation.

[33] Megginson, D. \& Clutterbuck, D. (1995). Mentoring in Action: A practical Guide for Managers. London: Kogan.

[34] Newman, B. M., \& Newman, R. P. 2012. Development Through Life: A Psychosocial Approach. Homewood: Dorsey Press.

[35] Noe, R. A. 1988. An investigation of the determinants successful assigned mentoring relationships. Personnel Psychology, 41, pp. 457-479.

[36] Noe, R. A., Greenberger, D. B., \& Wang, S. 2002. Mentoring: What we know and where we might go. New York: Elsevier Science.

[37] Nunally, J. C. \& Bernstein, I. H. (1994). Psychometric theory. New York: McGraw Hill.

[38] Oluga, S.O., C.O. Adewusi, \& H.A.L. Babalola, 2001. Basic communication skills. Lagos: Elpis Publishers.

[39] Pope, M. L. 2002. Community college mentoring: Minority student perception. Community College Review, 30(3), pp. 31-45.

[40] Ragin, R. B., \& Kram, E. K. (2007). The handbook of Mentoring at Work: Theory, research, and Practice. Log Angeles: Sage Publication. 
[41] Rayle, A. D., Kurpius, S. E. R., \& Arredondo, P. 2006. Relationship of self-beliefs, social support, and university comfort with the academic success of freshman college women. J. College Student Retention, 8(3), pp. 325-343.

[42] Ringle, C. M., Wende, S. \& Will, A. ( 2005). SmartPLS 2.0 M3, Available at http:// www.smartpls.de.

[43] Santos, S. J., \& Reigadas, E. T. 2002. Latinos in higher education: An evaluation of a university faculty mentoring program. Journal of Hispanic Higher Education, 1, pp. 4050 .

[44] Santos, S. J., \& Reigadas, E. T. 2005. Understanding the student-faculty mentoring process: Its effect on at-risk university students. J. College Student Retention, 6(3), 337357.

[45] Sekaran, U., \& Bougie, R. (2010). Research methods for business: A skill building approach (5th Edition). New York: John Wiley \& Sons.

[46] Stewart, J., \& Knowles, V. 2003. Mentoring in undergraduate business management programmes. Journal of European Industrial Training,27/2(3/4), 147-159.

[47] Sullivan, R. 2000. Entrepreneurial learning and mentoring. International Journal of Enterpreneurial Behavior and Research, 6(3), pp. 160-175.

[48] Tennenbaum, H. R., Crosby, F. J., \& Gliner, M. D. 2001. Mentoring relationships in graduate school. Journal of Vocational Behavior, 59, pp. 326-341.

[49] Tsai, W. C \& Tai, W. T. 2003. Perceived importance as a mediator of the relationship between training assignment and training motivation. Personal Review, 31(2), pp. 151163.

[50] Vieno, A., Santinello, M., Pastore, M., \& Perkins, D. D. 2007. Social support, sense of community in school, and self-efficacy as resources during early adolescence: An integrative model. Am J Community Psychol, 39, pp. 177-190.

[51] Wetzel, C.M. Kneebone, R.L., Woloshynowych, H., Moorthy, K., \& Darsy, A.D. 2006. The effects of stress on surgical performance. The American Journal of Surgery, 191(1), pp. 5-10.

[52] Yamnill, S. \& McLean, G. N. 2001. Theories supporting transfer of training. Human Resource Development Quarterly, 12, pp. 195-208.

[53] Young, R. W., \& Cates, C. M. 2005. Playful communication in mentoring. College Student Journal, 39(4), pp. 692-701.

[54] Zikmund, W. G. 2000. Business research methods ( $6^{\text {th }}$ Edition). Chicago: The Dryden Press.

[55] Zuraidah, A. R., Zaiton, H., Masiniah, M., Jamayah, S., Sabasiah, H., \& Abdul Halim, B. 2004. Pengenalan mentoring di Institusi Pengajian Tinggi. Kuala Lumpur: IBS. 